\title{
Prevalence of COVID-19 antibodies among operating room and critical care staff at a tertiary teaching hospital
}

\author{
A cross-sectional study
}

Sara H. Farsi, MBBS, Thamir A. Alandijany, PhD, Mansoor Radwi, MBBS, Ali Farsi, MBBS, Wadeeah Bahaaziq, MBBS, Ibrabim Abushoshah, MBBS, Sherif A. El-Kafrawy, PhD, Salma Alsayed, BSc, Esam I. Azhar, PhD, Abdulaziz Boker, MBBS.

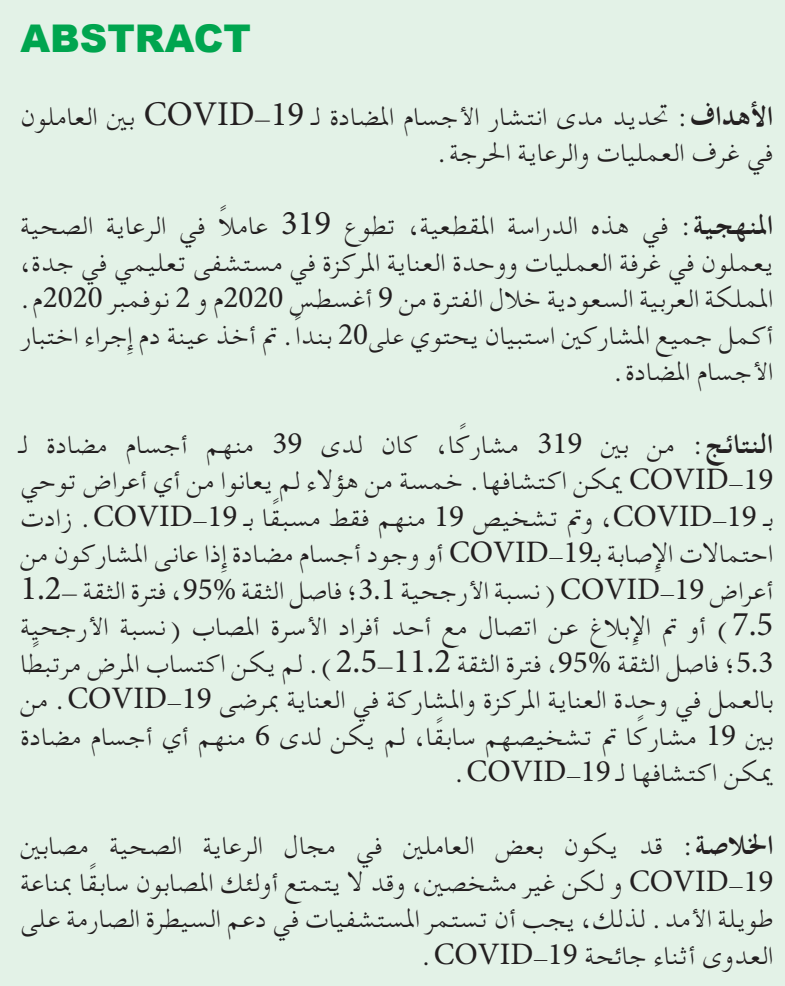

Objectives: To identify the prevalence of COVID-19 antibodies among operating room and critical care staff.

Methods: In this cross-sectional study, we recruited 319 Healthcare workers employed in the operation theater and intensive care unit of King Abdulaziz University Hospital (KAUH), a tertiary teaching hospital in Jeddah, Saudi Arabia between August 9, 2020 and November 2, 2020. All participants completed a 20 -item questionnaire on demographic data and COVID-19 risk factors and provided blood samples. Antibody testing was performed using an in-house enzyme immunoassay and microneutralization test.

Results: Of the 319 participants, 39 had detectable COVID-19 antibodies. Five of them had never experienced any symptoms suggestive of COVID-19, and only 19 were previously diagnosed with COVID- 19 . The odds of developing COVID-19 or having corresponding antibodies increased if participants experienced COVID-19 symptoms (odds ratio [OR], $3.1 ; 95 \%$ confidence interval [CI], 1.2-7.5) or reported contact with an infected family member (OR, 5.3; 95\% CI, 2.5-11.2). Disease acquisition was not associated with employment in the ICU and involvement in the intubation of or close contact with COVID-19 patients. Of the 19 previously diagnosed participants, 6 did not possess any detectable COVID-19 antibodies.

Conclusions: Healthcare workers may have undiagnosed COVID-19, and those previously infected may not have long-lasting immunity. Therefore, hospitals must continue to uphold strict infection control during the COVID-19 pandemic.

Keywords: infection control, immune reaction, healthcare worker, COVID-19, SARS-COV-2, ELISA, microneutralization assay, Saudi Arabia

Saudi Med J 2021; Vol. 42 (7): $742-749$ doi: $10.15537 /$ smj.2021.42.7.20210348

From the Department of Anesthesia and Critical Care (Farsi, Bahaaziq, Abushoshah, Boker), Faculty of Medicine, King Abdulaziz University; from the Special Infectious Agents Unit (Alandijany, El-Kafrawy, Alsayed, Azhar), King Fahd Medical Research Center, King Abdulaziz University; from the Department of Medical Laboratory Technology (Alandijany, El-Kafrawy, Alsayed, Azhar), Faculty of Applied Medical Sciences, King Abdulaziz University; from the Department of Hematology (Radwi), College of Medicine, University of Jeddah; from the Department of Surgery (Farsi), Faculty of Medicine, King Abdulaziz University Jeddah; from the Clinical Skills and Simulation Center (Boker), King Abdulaziz University, Jeddah; and from the Department of Nursing (Alsayed), Faculty of Al-Qunfudah Health Sciences, Umm Al-Qura University, Makkah, Kingdom of Saudi Arabia.

Received 28th February 2021. Accepted 17th May 2021.

Address correspondence and reprint request to: Dr. Sara Farsi, Department of Anesthesia and Critical Care, Faculty of Medicine, King Abdulaziz University, Jeddah, Kingdom of Saudi Arabia. E-mail: sfarsi@kau.edu.sa ORCID ID: http://orcid.org/0000-0001-7694-4057 
T he World Health Organization (WHO) declared the coronavirus disease (COVID-19) outbreak a global pandemic in March 2020. ${ }^{1}$ COVID-19 is highly infectious with a reproductive number (R0) between 1.4-2.5; however, a few studies suggest that this value could be higher. ${ }^{2}$ As of December 2020, there have been more than 80 million confirmed cases of COVID-19 worldwide, with approximately 1.5 million deaths. ${ }^{3}$ These cases include more than 100,000 infections among healthcare workers (HCWs) in the US alone, with exposure in a healthcare facility identified as the only possible source of infection in more than half of these cases. ${ }^{4-6}$ Healthcare workers care for critically ill and highly infectious patients while protecting themselves and other HCWs from infection. This is a massive challenge owing to the marked increase in hospital admissions during the ongoing pandemic, the high infectivity rate of COVID-19, and the shortage of personal protective equipment (PPE). ${ }^{7-9}$

Early research suggested that nosocomial COVID-19 infection rates may be significant; however, follow-up studies opposed this finding. ${ }^{10-12}$ The conflicting results may be attributable to better awareness and understanding of the disease, an improvement in the provision of PPE, and implementation of strict infection control measures. ${ }^{12}$ Certain procedures associated with aerosol generation, such as tracheal intubation, non-invasive ventilation, tracheotomy, and cardiopulmonary resuscitation, carry a higher risk of COVID-19 acquisition for HCWs, especially if they are not wearing adequate PPE. ${ }^{13}$

An additional factor contributing to the rapid spread of COVID-19 is transmission by asymptomatic and presymptomatic carriers. The viral load among symptomatic and asymptomatic patients is similar, and viral shedding is maximal prior to symptom onset. ${ }^{14}$ One study suggested that transmission by presymptomatic carriers may account for $48-62 \%$ of infections in the general population. ${ }^{15} \mathrm{~A}$ cross-sectional study that screened for COVID-19 among asymptomatic HCWs revealed that $3 \%$ tested positive. ${ }^{16}$ Seropositivity for antibodies among HCWs was $8.7 \%$ in a systematic review by Galanis et al. ${ }^{17}$ Asymptomatic HCWs may unknowingly transmit the disease to their families, other healthcare staff, and non-COVID-19 patients. These concerns have led to modifications in various protocols

Disclosure. Authors have no conflict of interests, and the work was not supported or funded by any drug company. in the healthcare system. ${ }^{18}$ All patients and HCWs are assumed to be potential hidden sources of infection. Therefore, appropriate personal protective equipment (PPE) must always be worn while in hospital.

Assessing infection rates in healthcare teams can assist in evaluating the effectiveness of infection control measures and identify areas of weakness. We hypothesized that we would find a high prevalence of antibodies among HCWs in critical care units and operating rooms due to their close contact with patients and their participation in aerosol-generating procedures. The aim of our study was to identify the prevalence of seropositivity for COVID-19 immunoglobulin G (IgG) among HCWs employed in the operating room and intensive care unit of a tertiary academic hospital in Jeddah, Saudi Arabia and to identify the associated risk factors.

Methods. A cross-sectional study was performed at the King Abdulaziz University Hospital (KAUH), Jeddah, Saudi Arabia. It is one of the largest tertiary hospitals in the western region of Saudi Arabia, with a 1000-bed capacity. It was the second largest hospital that admitted COVID-19 patients in Saudi Arabia during the peak of the pandemic.

We included hospital employees working in the operating room and critical care units in King Abdulaziz University Hospital during the COVID-19 pandemic between August 9, 2020 and November 2, 2020. The sample comprised nurses, allied health personnel, and physicians, including trainees.

We invited King Abdulaziz University Hospital employees to participate through announcements during teaching rounds and through personal invitations to eligible candidates. Healthcare workers who agreed to participate in the study were asked to sign an informed consent, fill in a structured questionnaire, and provide a venous blood sample.

We developed a 20-item questionnaire through a collaborative and iterative process. The research team performed an extensive literature review to identify reported risk factors for acquiring COVID-19, as well as the most common symptoms. Thereafter, the team developed a draft that was subsequently analyzed and edited several times by subgroups of the team. These subgroups analyzed the questions for content, established face-validity, and eliminated any leading, confusing, or double-barreled questions. The final questionnaire contained questions on participant demographics, risk factors for acquiring COVID-19, symptoms of COVID-19, and past diagnosis. It was then piloted on 16 participants to assess for clarity of 
content, and feedback was incorporated into the final questionnaire.

We used an indirect enzyme-linked immunoassay (ELISA) to identify virus-specific IgG in the blood samples. We screened the sera for the presence of anti-severe acute respiratory syndrome coronavirus 2 (SARS-CoV-2) IgG antibodies following a recently optimized and validated in-house ELISA protocol. ${ }^{19}$ We measured the optical density values for sera at 450 $\mathrm{nm}$ with considered values $>0.27$ as positive. This method is shown to provide $100 \%$ sensitivity and $98.4 \%$ specificity. ${ }^{19}$ We then confirmed all positive and equivocal test results using a microneutralization test (MNT), which represents the gold standard for antibody detection. We only considered patients whose sera tested positive using MNT as antibody-positive.

We obtained ethical approval from King Abdulaziz University Hospital and followed the principles of Helsinki Declaration. All patients provided informed consent for participation in the study. We gave the participants a random serial number each to maintain the anonymity of the results. Only the chief investigator had access to the participants' identity to provide participants with their results if requested.

We performed statistical analysis using the SPSS V.20 software package (SPSS, Chicago, IL, USA). For descriptive analysis, we presented continuous variables as means and standard deviations and summarized categorical variables using counts and percentages.

For comparative analysis, we used the Chi-square test to compare dichotomous data. Odds ratios estimated the magnitude of the association between COVID-19 acquisition or presence of antibodies and risk factors associated with COVID-19. We used independent samples t-tests to compare normally distributed continuous data, and Mann-Whitney $U$ tests to compare non-normally distributed continuous data.

Results. We recruited a total of 325 participants in the study. Of these, 6 were excluded because they did not provide a blood sample. We used ELISA to screen the blood samples from the study population initially. The samples that tested negative at this step were considered true negative. Thereafter, we used MNTs to confirm the status of all positive and equivocal results.

The baseline characteristics are detailed in Table 1. The mean age was 37 (range, 22-62) years. Most of the participants were female $(\mathrm{n}=162,51 \%)$ and the majority were from the Nursing Department ( $n=130,40.8 \%)$, followed by the Departments of Anesthesia ( $\mathrm{n}=71$, $22.3 \%)$, Surgery $(\mathrm{n}=54,16.9 \%)$, and Critical Care $(\mathrm{n}=31,9.7 \%)$. Of the 133 physicians who participated in the study, 55 (41\%) were classified as consultants, 40 $(30 \%)$ as registrars, and $36(29 \%)$ as residents.

Most participants did not report any history of chronic disease $(n=186,58 \%)$; among those who did, hypertension ( $\mathrm{n}=29,9 \%)$, asthma $(\mathrm{n}=19,6 \%)$, and diabetes $(n=13,4 \%)$ were the top 3 diseases reported. Only a minority were smokers $(n=29,9 \%)$.

Regarding COVID-19 risk factors, 119 (37\%) participants stated that they worked in the ICU, 118 (37\%) believed that they did not have enough PPE during the pandemic, $246(77 \%)$ reported having

Table 1 - Baseline characteristics for the 319 participants.

\begin{tabular}{|c|c|c|}
\hline Variable & $\mathbf{n}$ & $(\%)$ \\
\hline Age in years [mean $\pm S D](n=282)$ & $37.3 \pm 8.6$ & NA \\
\hline Female $(\mathrm{n}=298)$ & 162 & (54) \\
\hline $\begin{array}{l}\text { Division }(n=317) \\
\text { Nursing } \\
\text { Anesthesia } \\
\text { Surgery } \\
\text { Critical care } \\
\text { Respiratory therapy } \\
\text { Others }\end{array}$ & $\begin{array}{l}130 \\
71 \\
54 \\
31 \\
13 \\
20\end{array}$ & $\begin{array}{l}(40.8) \\
(22.3) \\
(16.9) \\
(9.7) \\
(4.1) \\
(6.3)\end{array}$ \\
\hline $\begin{array}{l}\text { Occupation } \\
\text { Nurse } \\
\text { Consultant } \\
\text { Registrar } \\
\text { Resident } \\
\text { Technician } \\
\text { Respiratory therapist } \\
\text { Others }\end{array}$ & $\begin{array}{c}312 \\
133 \\
55 \\
40 \\
36 \\
21 \\
14 \\
20\end{array}$ & $\begin{array}{l}(41.7) \\
(17.2) \\
(12.5) \\
(11.3) \\
(6.5) \\
(4.4) \\
(6.3)\end{array}$ \\
\hline $\begin{array}{l}\text { Chronic disease }(n=294) \\
\text { Hypertension } \dagger \\
\text { Asthma } \dagger \\
\text { Diabetes } \dagger \\
\text { Others }\end{array}$ & $\begin{array}{l}104 \\
34 \\
25 \\
17 \\
25\end{array}$ & $\begin{array}{l}(32.6) \\
(32.6) \\
(24.0) \\
(16.3) \\
(24.0)\end{array}$ \\
\hline Smoker & 35 & $(10.9)$ \\
\hline $\begin{array}{l}\text { Blood group } \\
\text { O } \\
\mathrm{A} \\
\mathrm{B} \\
\mathrm{AB} \\
\text { Don't know }\end{array}$ & $\begin{array}{c}300 \\
137 \\
79 \\
66 \\
17 \\
1\end{array}$ & $\begin{array}{l}(42.9) \\
(24.8) \\
(20.7) \\
(5.3) \\
(0.3)\end{array}$ \\
\hline $\begin{array}{l}\text { Number of participants with history of } \\
\text { COVID-19 infection }(n=311) \\
\text { Recovered at home } \\
\text { Admitted to hospital but did not require } \\
\text { oxygen }\end{array}$ & $\begin{array}{c}21 \\
4\end{array}$ & $\begin{array}{l}(84.6) \\
(13.4)\end{array}$ \\
\hline $\begin{array}{l}\text { Number of participants with symptoms of } \\
\text { COVID-19 infection }\end{array}$ & 226 & $(70.8)$ \\
\hline $\begin{array}{r}\dagger \text { Some participants had more than } \\
\text { COVID-19, coronavirus disease; RT-PC } \\
\text { polymerase chain reaction, NA }\end{array}$ & $\begin{array}{l}\text { ronic disea } \\
\text { verse transc } \\
\text { applicable }\end{array}$ & \\
\hline
\end{tabular}


had contact with a COVID-19 patient in the hospital during the pandemic, 125 (39\%) believed that they had contact with individuals who might have had COVID-19 outside the hospital, 101 (32\%) were part of the airway team, and $98(31 \%)$ had intubated a COVID-19 patient (Table 2).

Most participants ( $n=226,71 \%)$ reported having symptoms that could be attributed to COVID-19 since the beginning of the pandemic. However, only 131 $(58 \%)$ of the participants with symptoms suspected of having COVID-19. Twenty-four out of the 25 participants, who had been previously diagnosed with COVID-19, were highly suspected of contracting the disease and reported symptoms related to it. A majority of these patients had not been hospitalized and had recovered at home $(n=24,96 \%)$. Only one participant with confirmed COVID-19 required hospitalization and was classified as having had a mild infection that did not indicate a need for oxygen support.

Regarding COVID-19 IgG testing, 39 (12.2\%) samples were seropositive. Of the seropositive results, 20 participants (48\%) were not previously diagnosed with COVID-19. Of these, only 4 cases were considered as truly asymptomatic (participants showed no symptoms and were not suspected of having COVID-19) (Table 3).

Furthermore, of the 25 cases of COVID-19 previously confirmed using reverse transcriptase polymerase chain reaction (RT-PCR), only 19 (73.9\%) possessed antibodies against the virus. The prevalence of seropositivity among participants in various departments were as follows: 13 participants $(10 \%)$ in the Nursing department, 9 (13\%) Anesthesia, 6 (11\%) Surgery, and $5(16 \%)$ Critical Care. The prevalence of

Table 2 - Risk factors for acquiring COVID-19 infection.

\begin{tabular}{lcc}
\hline Variables & $\mathbf{n}$ & $(\%)$ \\
\hline $\begin{array}{l}\text { Contact with patient(s) diagnosed with } \\
\text { COVID-19 (n=310) }\end{array}$ & 246 & $(77.1)$ \\
$\begin{array}{l}\text { Contact with household member diagnosed with } \\
\text { COVID-19 (n=313) }\end{array}$ & 38 & $(11.9)$ \\
$\begin{array}{l}\text { Contact with non-household member diagnosed } \\
\text { with COVID-19 (n=309) }\end{array}$ & 125 & \\
$\begin{array}{l}\text { Working in ICU (n=314) } \\
\text { Part of airway team (n=312) }\end{array}$ & 119 & \\
Lack of PPE material (n=315) & 101 & $(37.3)$ \\
Have intubated patient(s) diagnosed with & 118 & $(37.0)$ \\
COVID-19 (n=313) & 98 & $(30.7)$ \\
\hline
\end{tabular}

ICU: intensive care unit, PPE: personal protective equipment seropositivity according to physician's classification were as follows: $5(10 \%)$ consultants, $7(18 \%)$ registrars, and $4(11 \%)$ residents.

The odds of seropositivity for COVID-19 increased if the participants had symptoms suggestive of COVID-19 (OR=3.1, 95\% CI=1.2-7.5; $p=0.01)$, had contact with family members who tested positive for COVID-19 (OR=5.3, 95\% CI=2.5-11.2; $p<0.001)$, suspected they had COVID-19 (OR=9.8, 95\% $\mathrm{CI}=4.4-19.1 ; \quad p<0.001), \quad$ and/or were previously tested for COVID-19 (OR=3.3, 95\% CI=1.5-6.9; $p=0.002)$. The odds decreased if the participants had blood group $\mathrm{O}(\mathrm{OR}=0.5,95 \% \mathrm{CI}=0.2-0.9 ; p=0.03$; Table 4). There was no statistical association between the presence of COVID-19 antibodies and age, history of chronic disease, previous contact with COVID-19 patients without full PPE (N95 mask, face shield, and gown), previous contact with COVID-19 patients, having intubated COVID-19 patient(s), employment in the ICU, or being part of an airway team.

On comparing participants who were previously diagnosed with COVID-19 to those who possessed COVID-19 antibodies but had not been previously diagnosed with COVID-19, we found no differences in terms of age, gender, history of chronic disease, lack of PPE, contact with or intubation of COVID-19 patients, participation in an airway or ICU team, and contact with family or non-family members with COVID-19.

On restricting the analysis to participants with previously diagnosed COVID-19, we found that those who were seronegative had acquired the infection earlier than those who were seropositive; the number of days between COVID-19 diagnosis and testing for

Table 3 - Results related to COVID-19 testing.

\begin{tabular}{|c|c|c|}
\hline Variables & $\mathbf{n}$ & $(\%)$ \\
\hline Antibodies positive for COVID-19* & 39 & $(12.2)$ \\
\hline $\begin{array}{l}\text { Participants previously diagnosed with COVID-19 } \\
\text { using RT-PCR }\end{array}$ & 19 & $(48.7)$ \\
\hline Participants had symptoms of COVID-19 & 34 & $(87.1)$ \\
\hline $\begin{array}{l}\text { Number of participants who suspected they had } \\
\text { COVID-19 infection }\end{array}$ & 103 & $(32.2)$ \\
\hline $\begin{array}{l}\text { Participants previously diagnosed with COVID-19 } \\
\text { using RT-PCR }\end{array}$ & 24 & $(23.3)$ \\
\hline Participants had symptoms of COVID-19 & 95 & $(92.2)$ \\
\hline $\begin{array}{l}\text { Participants who were antibody-positive but had no } \\
\text { prior diagnosis of COVID-19 }\end{array}$ & 10 & $(9.7)$ \\
\hline $\begin{array}{l}{ }^{*} \text { One sample was equivocal and was considered } \\
\text { analysis. RT-PCR: reverse transcription polyme }\end{array}$ & i & $\begin{array}{l}\text { final } \\
\text { tion }\end{array}$ \\
\hline
\end{tabular}


Table 4 - Association between risk factors for COVID-19 and developing COVID-19 infection or antibodies.

\begin{tabular}{|c|c|c|c|c|c|}
\hline \multirow{2}{*}{ Variable (yes/no) } & \multicolumn{2}{|c|}{ Blood Test } & \multirow[t]{2}{*}{ Odds ratio } & \multirow[t]{2}{*}{$95 \% \mathrm{CI}$} & \multirow[t]{2}{*}{$P$-value } \\
\hline & Negative & Positive & & & \\
\hline Contract with family member who has COVID-19 & $23 / 243$ & $15 / 30$ & 5.3 & $2.5-11.2$ & $<0.001$ \\
\hline Contract with non-family member who has COVID-19 & $103 / 163$ & $21 / 22$ & 1.4 & $0.7-2.6$ & 0.314 \\
\hline History of chronic disease $\dagger$ & $107 / 159$ & $21 / 27$ & 1.3 & $0.6-2.4$ & 0.417 \\
\hline Presence of COVID-19 symptoms & $181 / 85$ & $39 / 6$ & 3.1 & $1.2-7.5$ & 0.011 \\
\hline Lack of PPE & $177 / 95$ & $24 / 21$ & 1.5 & $0.8-3.0$ & 0.160 \\
\hline Contact with patient(s) with COVID-19 & $203 / 63$ & $38 / 7$ & 1.6 & $0.7-4.0$ & 0.227 \\
\hline Working In ICU & $94 / 172$ & $22 / 23$ & 1.8 & $0.9-3.3$ & 0.082 \\
\hline Part of Airway team & $85 / 181$ & $16 / 29$ & 1.2 & $0.6-2.3$ & 0.633 \\
\hline Participants have intubated patient with COVID-19 & $79 / 187$ & $18 / 27$ & 1.6 & $0.8-3.0$ & 0.168 \\
\hline Participants had previously tested for COVID-19 & $119 / 147$ & $35 / 10$ & 4.3 & $2.1-9.0$ & $<0.001$ \\
\hline Participants have suspected they had COVID-19 infection & $67 / 199$ & $34 / 11$ & 8.1 & $3.8-17.4$ & $<0.001$ \\
\hline Participants have a blood group O (vs. other type) & $122 / 128$ & $14 / 31$ & 0.5 & $0.2-0.9$ & 0.028 \\
\hline Participants are female (versus male) & $108 / 141$ & $24 / 21$ & 1.5 & $0.8-2.8$ & 0.216 \\
\hline
\end{tabular}

PPE: personal protective equipment, ICU: intensive care unit

COVID-19 antibodies was 103 (68) days (mean, SD) in the seronegative group and 74 (33) days (mean, SD) in the seropositive group. However, this difference was not statistically significant $(p=0.2)$. The 2 groups did not differ in terms of age, gender, history of chronic disease, lack of PPE, contact with or intubation of COVID-19 patients, participation in the airway or ICU team, and contact with family or non-family members with COVID-19.

Discussion. Healthcare workers in critical care units and operating rooms are at high risk of acquiring COVID-19 due to routine exposure to infected patients, particularly when participating in aerosolgenerating procedures. However, in our study, we did not find a significant association between HCW exposure to patients with COVID-19 and testing positive for the disease antibodies. Nine months after the beginning of the pandemic, $7.8 \%$ of the HCWs that participated in our study had been previously diagnosed with COVID-19 and $12.2 \%$ were seropositive for COVID-19 antibodies. In other published studies, the seroprevalence of COVID-19 antibodies among HCWs ranged between $0.34 \%$ and $24 \% .{ }^{20-23}$ This large variation could be secondary to sample size, participant inclusion and exclusion criteria, COVID-19 prevalence in a geographic area, availability of COVID-19 IgG testing, and the period in the pandemic when the study was conducted.
Hospital settings are not the only areas where HCWs may acquire COVID-19. In our study, the odds of testing seropositive for COVID-19 IgG were higher among HCWs who had an infected family member. We found no significant increase in infection rate among HCWs who were exposed to or even intubated COVID-19 patients. Healthcare workers would naturally be more cautious at work due to the known presence of infected individuals, as well as strict workplace guidelines that mandate HCWs to take all precautions. Previous studies have shown that appropriate PPE can reduce transmission of respiratory pathogens by $90 \% .{ }^{24}$ These findings emphasize the importance of maintaining infection control precautions both inside and outside hospitals. The apparent low rate of infected HCWs may encourage hospitals to reopen occupational therapy (OT) services. Nonetheless, these results need to be interpreted with extreme caution.

The first COVID-19 case in Saudi Arabia was identified on March 4, 2020. The Government of Saudi Arabia implemented policies to curb infection rates, such as declaring full or partial curfews, shutting non-essential medical services, instructing academic institutions to switch to online teaching, and conducting rapid testing and isolation for those who were infected with COVID-19. ${ }^{25,26}$ At the time of this study, there were 364,929 COVID-19 cases (9,736 per million) and 6,323 deaths reported in Saudi Arabia. ${ }^{27}$ From the beginning of the pandemic until the end of 
November 2020, there had been 25,204 COVID-19 patients at King Abdulaziz University Hospital. As part of infection control measures implemented since the beginning of the pandemic, all staff were required to attend a newly established simulation-based PPE course and conduct in situ simulation drills. Hospital visitors were limited. All admitted staff and visitors were screened for fever and were instructed to wear a facemask. Specialized protocols were developed to identify possible infections. COVID-19-confirmed and suspected patients were kept in designated wards, operational rooms, and critical care units. In order to preserve resources and limit the viral spread, the number of active operating rooms was decreased from 14 to 4 , and only urgent, and emergency surgeries were performed. The decrease in the number of functioning OTs may have led to a decreases in disease transmission by preserving PPE and limiting exposure of HCWs to infected patients. With a decrease in hospital healthcare services, there has also been a decrease in exposure to other HCWs. The number of critical care beds was increased from 25 to 50 . A specialized intubation team was assigned to manage the airway and intubation of all COVID-19 patients throughout the hospital. Online grand rounds were used to reinforce infection control precautions and provide new updates on COVID-19 patient management guidelines.

Many of the physicians who tested positive had an unrecognized COVID-19 infection. In our study, 20 (6.2\%) HCWs were seropositive for COVID-19 IgG yet were never diagnosed with COVID-19. Of these, 4 participants (1.2\%) had never experienced symptoms suggestive of COVID-19. Other studies show a prevalence of asymptomatic infections ranging from $17.1-27 \%$ among HCWs. ${ }^{21,28}$ These asymptomatic individuals can shed the virus for up to 26 days. ${ }^{29}$ Furthermore, infected individuals may not exhibit symptoms for as long as 11 days after exposure. ${ }^{30}$ Therefore, it remains essential that HCW continue to maintain infection control measures and undertake social distancing precautions regardless of symptoms.

An interesting finding in our study was the absence of antibodies from the blood samples of $24 \%$ of patients $(n=6)$ who had been previously diagnosed with COVID-19 using RT-PCR. A possible explanation could be that the COVID-19 RT-PCR results of some participants may have been false positives. A systematic review by Arevalo-Rodriguez et $\mathrm{al}^{31}$ showed that RT-PCR has 70\% sensitivity and 95\% specificity. An alternative theory is that antibodies against COVID-19 may not be long-lasting or that patients may have never mounted an antibody response. A study by Long et $\mathrm{al}^{30}$ showed that $40 \%$ of COVID-19 patients were seronegative after 8 weeks. Figueirdo-Campos et $\mathrm{a}^{32}$ found that only $90 \%$ of confirmed patients possessed antibodies 6 months after the infection. This contradicts the idea proposed by many governments to develop herd immunity through infection. Further, these factors may limit the sensitivity of antibody testing as a way of diagnosing past infections. Additionally, the loss of antibodies demonstrates the need to vaccinate all HCWs, regardless of whether they previously acquired the infection or not.

We also found a statistically significant increase in the seroprevalence of COVID-19 antibodies among participants with a non-O blood group. Previous studies have found a decrease in the infection rate of both SARS-COV-1 and SARS-COV-2 among people with O blood group. ${ }^{33-35}$ This may be a result of naturally occurring antibodies in type $\mathrm{O}$ blood, such as anti-A, preventing the virus from binding to angiotensinconverting enzyme 2 -expressing cell lines. ${ }^{36}$

Our study had several limitations. First, the prevalence rate may be misleading because participation was voluntary. Healthcare workers who were already diagnosed with COVID-19 may have been less curious about their antibody status or were worried about discrimination based on the results. Second, recall bias may have influenced the participants' answers regarding the survey questions when recalling symptoms or exposure. Third, some HCWs may not have developed antibodies at the time of testing as antibodies can take up to 19 days to develop. ${ }^{37}$ Fourth, since asymptomatic patients are more likely to remain seronegative for COVID-19 IgG, this may have resulted in a falsely low rate of asymptomatic HCWs. ${ }^{20}$ Finally, there have been reports of possible cross-reactivity with other viral strains. However, the test used in this study has been proven to have a high specificity. ${ }^{19}$

In conclusion, maintaining appropriate infection precautions appear to prevent disease spread, even in high-risk settings. Furthermore, prior infection with COVID-19 may not guarantee life-long immunity to the virus. Therefore, HCWs who have acquired the virus must continue to adhere to all infection control precautions. Future studies should aim to evaluate factors that may affect the duration of protection by these antibodies and whether antibodies produced by vaccination have a different lifespan. 
Acknowledgment. We would like to thank Ms. Binny Jacobs, Ms. Reem Komosani, Mr. Arif Bukhari, Mr. Abdullah Alghamdi, Mrs. Judy Soriano and Mrs. Leonora Raymundo for their hard work and contributions that have made this project possible.

\section{References}

1. World Health Organization. General's opening remarks at the media briefing on COVID-19; March 112020 [cited Jan 17, 2021]. Available from: https://www.who.int/director-general/ speeches/detail/who-director-general-s-opening-remarks-atthe-media-briefing-on-covid-19---11-march-2020.

2. Liu Y, Gayle AA, Wilder-Smith A, Rocklöv J. The reproductive number of COVID-19 is higher compared to SARS coronavirus. J Travel Med 2020; 27: 1-4.

3. World Health Organization. Coronavirus disease (COVID-19) dashboard. [cited 2021]. Available from: https://covid19.who. int

4. Barrett ES, Horton DB, Roy J, Gennaro ML, Brooks A, Tischfield J, et al. Prevalence of SARS-CoV-2 infection in previously undiagnosed health care workers at the onset of the U.S. COVID-19 epidemic. medRxiv 2020;

5. CDC COVID-19 Response Team. Characteristics of health care personnel with COVID-19 - United States, February 12-April 9, 2020. MMWR Morb Mortal Wkly Rep 2020; 69: 477-481.

6. Hughes MM, Groenewold MR, Lessem SE, Xu K, Ussery EN, Wiegand RE, et al. Update: characteristics of health care personnel with COVID-19 - United States, February 12-July 16, 2020. MMWR Morb Mortal Wkly Rep 2020; 69: 1364-1368.

7. Li R, Rivers C, Tan Q, Murray MB, Toner E, Lipsitch M. The demand for inpatient and ICU beds for COVID-19 in the US: lessons from Chinese cities. medRxiv 2020. doi: 10.1101/2020.03.09.20033241

8. Cohen J, Rodgers YVM. Contributing factors to personal protective equipment shortages during the COVID-19 pandemic. Prev Med 2020; 141: 106263.

9. Ahmed J, Malik F, Bin ArifT, Majid Z, Chaudhary MA, Ahmad $\mathrm{J}$, et al. Availability of personal protective equipment (PPE) among US and Pakistani doctors in COVID-19 pandemic. Cureus 2020; 12: e8550.

10. Zhou Q, Gao Y, Wang X, Liu R, Du P, Wang X, et al. Nosocomial infections among patients with COVID-19, SARS and MERS: a rapid review and meta-analysis. Ann Transl Med. 2020; 8: 629.

11. Rhee C, Baker M, Vaidya V, Tucker R, Resnick A, Morris $\mathrm{CA}$, et al. Incidence of nosocomial COVID-19 in patients hospitalized at a large US Academic Medical Center. JAMA Netw Open 2020; 3: e2020498.

12. Rickman HM, Rampling T, Shaw K, Martinez-Garcia G, Hail L, Coen P, et al. Nosocomial transmission of COVID-19: a retrospective study of 66 hospital-acquired cases in a London teaching hospital. Clin Infect Dis 2020; 72: 690-693.

13. Chatterjee P, Nagi N, Agarwal A, Das B, Banerjee S, Sarkar $S$, et al. The 2019 novel coronavirus disease (COVID-19) pandemic: a review of the current evidence. Indian J Med Res 2020; 151: 147-59.

14. Huff HV, Singh A. Asymptomatic transmission during the COVID-19 pandemic and implications for public health strategies. Clin Infect Dis 2020; 71: 2752-2756.
15. Ganyani T, Kremer C, Chen D, Torneri A, Faes C, Wallinga J, et al. Estimating the generation interval for coronavirus disease (COVID-19) based on symptom onset data, March 2020. EURO Surveill 2020; 25. ES.2020.25.17.2000257.

16. Rivett L, Sridhar S, Sparkes D, Routledge M, Jones NK, Forrest $S$, et al. Screening of healthcare workers for SARS-CoV-2 highlights the role of asymptomatic carriage in COVID-19 transmission. eLife 2020; 9: e58728.

17. Galanis P, Vraka I, Fragkou D, Bilali A, Kaitelidou D. Seroprevalence of SARS-CoV-2 antibodies and associated factors in health care workers: a systematic review and metaanalysis. J Hosp Infect 2020; 108: 120-134.

18. Schwartz J, King CC, Yen MY. Protecting healthcare workers during the coronavirus Disease 2019 (COVID-19) outbreak: lessons from Taiwan's severe acute respiratory syndrome response. Clin Infect Dis 2020; 71: 858-860.

19. Alandijany TA, El-Kafrawy SA, Tolah AM, Sohrab SS, Faizo AA, Hassan AM, et al. Development and optimization of in-house ELISA for detection of human IgG antibody to SARS-CoV-2 full length spike protein. Pathogens 2020; 9: 803.

20. Fukuda H, Seyama K, Ito K, Hori S, Wakita M, Saito K, et al. SARS-CoV-2 seroprevalence in healthcare workers at a frontline hospital in Tokyo. Research Square 2020. doi: 10.21203/rs.3.rs-96870/v1

21. Shields A, Faustini SE, Perez-Toledo M, Jossi S, Aldera E, Allen JD, et al. SARS-CoV-2 seroprevalence and asymptomatic viral carriage in healthcare workers: a cross-sectional study. Thorax 2020; 75: 1089-1094.

22. Moscola J, Sembajwe G, Jarrett M, Farber B, Chang T, McGinn T, et al. Prevalence of SARS-CoV-2 antibodies in health care personnel in the New York City Area. JAMA 2020; 324: 893-895.

23. Fernández-Rivas G, Quirant-Sánchez B, González V, Doladé M, Martinez-Caceres E, Pińa M, et al. Seroprevalence of SARS-CoV-2 IgG specific antibodies among healthcare workers in the northern metropolitan area of Barcelona, Spain, after the first pandemic wave. medRxiv 2020; 06: 20135673.

24. Gralton J, McLaws ML. Protecting healthcare workers from pandemic influenza: N95 or surgical masks? Crit Care Med 2010; 38: 657-667.

25. Alandijany TA, Faizo AA, Azhar EI. Coronavirus disease of 2019 (COVID-19) in the Gulf Cooperation Council (GCC) countries: current status and management practices. I Infect Public Health 2020; 13: 839-842.

26. Naar I. Timeline: here are all the measures taken by Saudi Arabia to combat the coronavirus; 2020, May 20. Al Arabiya English [cited 2021 Jan 17]. Available from: https://english. alarabiya.net/en/features/2020/03/28/Timeline-Saudi-Arabias-proactive-measures-to-combat-the-COVID-19-coronavirus.

27. COVID 19 dashboard: Saudi Arabia. Ministry of Health [cited 2021 Jan 17]. Available from: https://covid19.moh.gov.sa.

28. Treibel TA, Manisty C, Burton M, McKnight Á, Lambourne J, Augusto JB, et al. COVID-19: PCR screening of asymptomatic health-care workers at London hospital. Lancet 2020; 395: 1608-1610.

29. Long QX, Tang XJ, Shi QL, Li Q, Deng HJ, Yuan J, et al. Clinical and immunological assessment of asymptomatic SARS-CoV-2 infections. Nat Med 2020; 26: 1200-1204. 
30. McAloon C, Collins Á, Hunt K, Barber A, Byrne AW, Butler $F$, et al. Incubation period of COVID-19: a rapid systematic review and meta-analysis of observational research. BMJ Open 2020; 10: e039652.

31. Arevalo-Rodriguez I, Buitrago-Garcia D, Simancas-Racines D, Zambrano-Achig P, Del Campo R, Ciapponi A, et al. Falsenegative results of initial RT-PCR assays for COVID-19: A systematic review. PLoS One 2020; 15: e0242958.

32. Figueiredo-Campos P, Blankenhaus B, Mota C, Gomes A, Serrano M, Ariotti S, et al. Seroprevalence of anti-SARS-CoV-2 antibodies in COVID-19 patients and healthy volunteers up to 6 months post disease onset. Eur J Immunol 2020; 50: 2025-2040.

33. Fan Q, Zhang W, Li B, Li DJ, Zhang J, Zhao F. Association Between ABO Blood Group system and COVID-19 susceptibility in wuhan. Front Cell Infect Microbiol 2020; 10 : 404.
34. Zhao J, Yang Y, Huang H, Li D, Gu D, Lu X, et al. Relationship between the ABO blood group and the COVID-19 susceptibility. Clin Infect Dis 2020; 4: ciaa1150.

35. Cheng Y, Cheng G, Chui CH, Lau FY, Chan PK, Ng MH, et al. ABO blood group and susceptibility to severe acute respiratory syndrome. JAMA 2005; 293: 1450-1451.

36. Guillon P, Clément M, Sébille V, Rivain JG, Chou CF, Ruvoën-Clouet $N$, et al. Inhibition of the interaction between the SARS-CoV spike protein and its cellular receptor by anti-histo-blood group antibodies. Glycobiology 2008; 18: 1085-1093.

37. Long QX, Liu BZ, Deng HJ, Wu GC, Deng K, Chen YK, et al. Antibody responses to SARS-CoV-2 in patients with COVID-19. Nat Med 2020; 26: 845-848.

38. To KK-W, Cheng VC-C, Cai JP, Chan KH, Chen LL, Wong $\mathrm{LH}$, et al. Seroprevalence of SARS-CoV-2 in Hong Kong and in residents evacuated from Hubei Province, China: a multicohort study. The Microbe 2020; 1: e111-e118. 